\title{
Laser-Induced Streams in Liquids Depending on Focusing Conditions of Pulse-Periodic Femtosecond Laser Radiation
}

\author{
S.Yu. Lavrentyev, N.G. Solovyov, A.N. Shemyakin, M.Yu. Yakimov \\ Ishlinsky Institute for Problems in Mechanics Russian Academy of Sciences, \\ Moscow, 119526, Russia \\ yakimov@lantanlaser.ru
}

\begin{abstract}
The paper is devoted to generation and observing quasi-stationary flows under the effect of the focused pulse-periodic femtosecond laser radiation on liquid solvents: water, heavy water, alcohols, ketones, chlormetanes. The mechanism inducing directional flows appears to be directional collapse of the gas bubbles produced by multiphoton dissociation in a focused laser beam. Formation of the flows had being observed with schlieren technique and or framing small gas bubbles illuminated by visible laser beam converted to the line. Absorption coefficients of focused and unfocused femtosecond laser radiation in the fluids were also measured. In experiments with laser pulses of $450 \mathrm{fs}$ at $1.023 \mathrm{~nm}$ wavelength with pulse energy from 10 to $220 \mathrm{uJ}$ and repetition rate $1.43 \div 10 \mathrm{kHz}$ stationary flows of fluids were originated from the laser beam waist directed along or transversely (in most cases) to the laser beam. The streams along the laser axis in both directions were observed under low pulse power $(10 \div 20 \mathrm{uJ})$ provided precise lens adjustment without astigmatism or self-focusing. The tests show that single beam waist of $10 \div 20$ um in diameter and $100 \div 200$ um long generates two narrow jets along the beam axis in both directions from the waist. Lens displacement transversely to the beam leads to splitting beam waist in two astigmatic foci. Both foci generate axial flows directed toward each other that collide in the gap between foci, forming synthetic transverse flow.

The increase of the pulse energy and focal point intensity were followed by nonlinear selffocusing forming filament like beam waist up to $14 \mathrm{~mm}$ long. Repeating cycles of selffocusing and defocusing produce several energy deposition zones along the filament beam waist, each one generating separate streams along the beam axis. Colliding of the contradirected streams gave rise to complex flow pattern along and transversely to the beam axis.
\end{abstract}

Key words: laser-induced flows in liquids, femtosecond laser, laser beam self-focusing, multiphoton dissociation, laser beam interaction with liquids, laser processing.

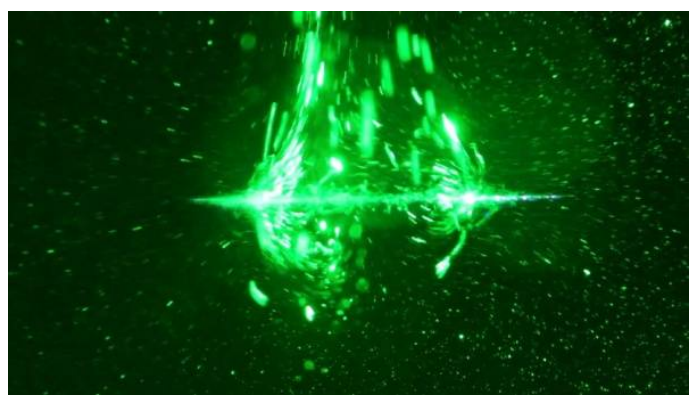

Video frame of the established flow pattern in heavy water in self-focused beam waist of pulse-periodic femtosecond laser. The flow pattern is created by microbubbles of dissociated heavy water illuminated by green "laser sheet". Intense contra-directed streams injected along laser beam collide and spread around forming streaks apart from the laser beam axis. Laser pulse duration and energy: $\tau=450 \mathrm{fs}, E_{p}=125 \mu \mathrm{J} /$ pulse, repetition rate $v_{r}=3.33 \mathrm{kHz}$. Frame size $9 \times 5 \mathrm{~mm}^{2}$. Laser beam is directed from left to right; focuser $f$-number is $f / 17$. 


\title{
Лазерно-индуцированные потоки в жидкостях в зависимости от условий фокусировки излучения фемтосекундного лазера
}

\author{
С.Ю. Лаврентьев, Н.Г. Соловьев, А.Н. Шемякин, М.Ю. Якимов \\ Федеральное государственное бюджетное учреждение науки \\ Институт проблем механики им. А.Ю. Иилинского РАН, \\ Россия, Москва, 119526, проспект Вернадского 101-1 \\ yakimov@lantanlaser.ru
}

\begin{abstract}
Аннотация
Данная работа посвящена получению и наблюдению квазистационарных потоков при воздействии сфокусированного импульсно-периодического излучения фемтосекундного импульсно-периодического лазера на жидкие растворители: воду, спирты, кетоны, хлорметаны. Вероятная причина образования стационарного потока - направленный коллапс газовых пузырьков, образующихся под действием лазерного излучения в результате многофотонной диссоциации. Образование потоков наблюдалось теневым методом, а также путем лазерной подсветки газовых пузырьков субмиллиметрового размера. В экспериментах измерялись коэффициенты поглощения сфокусированного и несфокусированного излучения фемтосекундного лазера в исследуемых жидкостях.

В экспериментах с импульсами длительностью 450 фс, длиной волны 1.023 мкм при энергии в импульсе от 10 до 220 мкДж и частоте повторения $1.43 \div 10$ кГц возникали стационарные потоки из области фокальной перетяжки вдоль оси лазерного луча, а также в перпендикулярном направлении.

Поток вдоль оси луча, исходящий из точки фокуса в обоих направлениях, наблюдался при малой энергии в импульсе $(10 \div 20$ мкДж) при условии точной настройки положения линзы, гарантирующей отсутствие астигматизма. В экспериментах в отсутствие астигматизма и самофокусировки в отдельной фокальной перетяжке диаметром 10-20 мкм и длиной 100-200 мкм формировался поток в виде двух узких струй вдоль оси луча в обе стороны от перетяжки. Смещение фокусирующей линзы в поперечном направлении относительно оси луча ведет к появлению двух астигматических фокусов, при достаточном расстоянии между которыми генерируются встречные осевые потоки, которые, сталкиваясь, растекаются в стороны, образуя синтетический поток в направлении, перпендикулярном лазерному лучу

При увеличении энергии в импульсе и интенсивности излучения в области фокуса усиливается эффект нелинейной самофокусировки и образуется участок луча в филамента длиной до 14 мм. Вследствие повторяющегося процесса самофокусировки и дефокусировки на протяжении филамента возникает несколько областей высокой интенсивности, каждая из которых генерирует осевые потоки, как отдельная перетяжка в экспериментах с малой энергией в импульсе. Столкновение встречных осевых потоков порождает сложную картину течений вдоль и поперек оси лазерного луча.
\end{abstract}

Ключевые слова: лазерно-индуцированные потоки в жидкостях, самофокусировка, многофотонная диссоциация, фемтосекундный лазер, лазерные технологии. 


\section{1. Введение}

Вопросы оптико-гидродинамического взаимодействия лазерного излучения с жидкостями исследуются в связи с применениями в нанотехнологиях и химических технологиях для задач манипулирования микрообъектами, производства растворов наночастиц, технологиях обработки материалов под слоем жидкости и т.п. [1-5].

В работах $[6,7]$ авторы сообщали о наблюдении квазистационарных направленных микропотоков, создаваемых в газе за счет поглощения некоторой доли излучения импульсно-периодического фемтосекундного лазера. Направленное движение газа возникало в результате релаксации (коллапса) области горячего газа пониженной плотности, возникавшей вследствие многофотонной ионизации вблизи фокальной перетяжки лазерного луча и последующего быстрого расширения нагретого ионизованного газа. Стационарное течение было результатом периодического повторения этого процесса с частотой повторения импульсов, интенсивность и направление потока определялись формой фокальной перетяжки и менялись при изменении степени астигматизма при фокусировке луча, что давало возможность управления интенсивностью и направлением создаваемого микропотока.

Ряд работ (например, [8-10]) посвящен исследованию схожих динамических механизмов образования направленных струй в жидкостях. В жидкостях направленное движение может возникать, например, вследствие асимметричного коллапса газовых пузырьков, образующихся при лазерном воздействии [8] - явлении, во многом схожем с коллапсом области пониженной плотности газа, возникающей при оптическом пробое. При фокусировке излучения фемтосекундного лазера в жидкости многофотонные процессы, идущие при высокой интенсивности лазерного излучения вблизи фокальной перетяжки, приводят, в первую очередь, к диссоциации молекул жидкости с образованием газовых пузырьков, сходных с кавитационными [10]. При схлопывании газовых пузырьков направленные струи формируются в том случае, когда во время схлопывания на пузырек воздействует гидродинамическое возмущение с определенной стороны, например, отраженное от расположенной поблизости стенки или от быстро расширяющегося или, наоборот, коллапсирующего поблизости другого пузырька [9]. В импульсно-периодическом режиме с достаточно большой частотой повторения импульсов коллапсирующие пузырьки будут находиться под постоянным воздействием гидродинамических возмущений, распространяющихся преимущественно вдоль оси лазерного луча или вдоль филаментов в случае самофокусировки (филаментации) $[2,11]$. Поэтому стоит ожидать преимущественного направления образующихся струй вдоль оси лазерного луча. Как показано ниже, наряду с продольными течениями возникают течения в поперечном лазерному лучу направлении, образующиеся в результате столкновения встречных продольных потоков. В литературе можно найти сообщения и о других механизмах возникновения потоков в жидкостях под действием лазерного излучения. Исключая термокапиллярные и электрооптические механизмы, как не имеющие отношения к предмету данной статьи, можно отметить пондеромоторный механизм [18] и механизм генерации ультразвуковых волн содержащимися в жидкости наночастицами под действием лазерного излучения [19].

Данная работа посвящена получению и наблюдению квазистационарных потоков в жидкостях при воздействии импульсно-периодического лазерного излучения и исследованию самых общих свойств образующихся течений.

\section{2. Постановка эксперимента}

В экспериментах использовался фемтосекундный лазер Amplitude Systemes s-Pulse c фиксированными уровнями энергии в импульсе 13, 135 и 250 мкДж, частотами повторения импульсов $1.43,1.67,3.33,5$ и 10 кГц при длительности импульсов не более 450 фс. Основная длина волны излучения 1.023 мкм, диаметр луча 2.6 мм, параметр распространения $\mathrm{M}^{2}<1.3$, что соответствует угловой расходимости не более 0.69 мрад (полный угол). 
Лазерное излучение фокусировалось двояковыпуклыми кварцевыми линзами с соотношением радиусов кривизны поверхностей $1: 4$, обеспечивающим минимум сферической аберрации, с параметрами фокусировки $f / 5 n$ и $f / 12.8 n$, где $n$ - коэффициент преломления среды. Минимальный диаметр луча в перетяжке фокуса составлял, соответственно, не более 10 мкм для первого случая и около 20 мкм для второго.

Схемы подвода и фокусировки излучения показаны на рис. 1. Сфокусированное излучение вводилось в жидкость через плоскую стенку прямоугольной кюветы из кварцевого стекла оптического качества толщиной 3 мм. На выходе из кюветы с жидкостью лазерное излучение попадало на приемную площадку калориметрического измерителя средней мощности лазерного излучения. Также как и в предыдущих экспериментах $[6,7]$, в которых излучение фокусировалось внеосевым параболоидом, при смещения центра линзы $f / 5 n$ относительно оси лазерного излучения на $1 \div 2$ мм возникал астигматизм с разделением фокальных перетяжек на величину $1 \div 2$ мм, заметно превышающую длину перетяжек. Эту возможность важно было учитывать при интерпретации результатов. Пример расчета астигматизма, возникающего при смещении и наклоне линзы относительно оси лазерного луча, методом многолучевой оптики дан в Приложении 1 в конце статьи.

a)

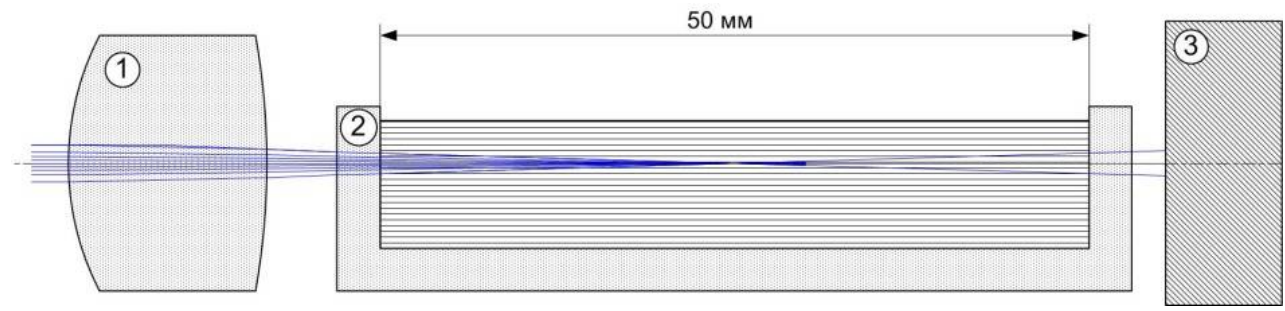

b)

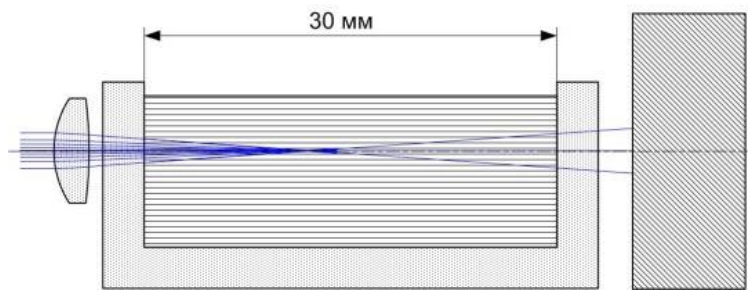

c)

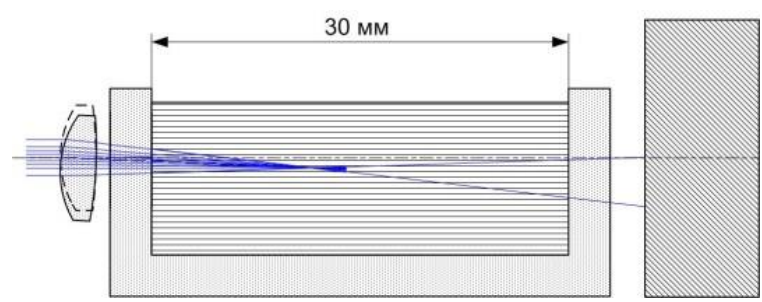

Рис. 1. Схемы фокусировки излучения импульсно-периодического фемтосекундного лазера $\lambda=1.023$ мкм в прямоугольных кварцевых кюветах с исследуемыми жидкостями. Излучение падает слева направо, исходный диаметр луча 2.6 мм. Слева от кюветы с жидкостью 2 находится фокусирующая линза 1 , справа - поглотитель излучения калориметрического измерителя мощности 3. $a)$ линза с фокусным расстоянием $f=33.3$ мм $(f / 12.8 n$, где $n$ - коэффициент преломления жидкости); $b), c$ ) линза с фокусным расстоянием $f=13.2$ мм $(f / 5 n) ; c)$ схема фокусировки с искусственным астигматизмом - линза смещена относительно оси лазерного луча на 0.7 мм вниз и наклонена на 1 градус вправо, положение точной настройки линзы и исходная ось луча показаны пунктиром. Ход лучей рассчитан методом многолучевой оптики для $n=1.325$ (вода)

Исследования проводились в воде, ацетоне, спиртах, хлорметанах. Во всех названных жидкостях, за исключением второстепенных особенностей, связанных с различием в коэффициентах преломления и поглощения, наблюдалась сходная картина лазерно-индуцированных течений. При интерпретации результатов наблюдения лазерно-индуцированных течений важно было учитывать поглощение лазерного излучения при прохождении в 
жидкости, а также нелинейно-оптическое явление самофокусировки, вызываемое зависимостью коэффициента преломления от интенсивности лазерного излучения. Необходимые оптические характеристики жидкостей даны в табл. 1. Соотношения для оценки эффекта самофокусировки даны в Приложении 2.

Образующийся поток жидкости наблюдали теневыми методами, просвечивая кювету с жидкостью пучком широкополосного излучения от точечного лазерно-плазменного источника ЛПИ-50 (аналогично [6,7]). Другая возможность наблюдения потоков возникала благодаря присутствию в жидкости пузырьков газа, выбрасываемых с потоком из зон повышенной интенсивности в области перетяжек, в которых происходило образование газовых пузырьков вследствие многофотонной фотодиссоциации. Пузырьки подсвечивались лучом вспомогательного лазера с длиной волны 532 нм, развернутого с помощью цилиндрической линзы в линию и сфокусированного сферической линзой в «световой лист», имеющий максимальную интенсивность в области взаимодействия излучения фемтосекундного лазера с жидкостью. Теневые изображения и картины движения пузырьков регистрировалась с помощью видеосъемки. Подмешивание в жидкость калиброванных микрочастиц для визуализации потока в данной постановке исключено, поскольку частицы повлияли бы на распространение, рассеяние и поглощение излучения фемтосекундного лазера и на механизмы оптико-гидродинамических явлений [19].

\section{1. Поглощение несфокусированного излучения фемтосекундного лазера в жидкостях}

Чтобы использовать соотношение (П2.4) (Приложение 2) для оценки величины смещения точки фокуса из-за эффекта самофокусировки, необходимо учитывать поглощение излучения при распространении от стенки кюветы до точки фокуса. Данные по коэффициентам поглощения излучения с длиной волны $\lambda=1.023$ мкм в исследуемых растворителях можно найти в справочной литературе, например [1], а также в оригинальных работах [16].

Тем не менее, для того, чтобы учесть возможное влияние особенностей используемых в экспериментах жидкостей, а также специфику применяемого источника лазерного излучения - лазера сверхкоротких импульсов, авторы данной работы провели измерение коэффициентов поглощения несфокусированного излучения в исследуемых растворителях. Измерения проводились при двух уровнях энергии импульса в точке измерения (энергия на выходе лазера минус потери в зеркалах системы подвода излучения) $E_{0}=125$ мкДж (частоты следования 3.3 и 10 кГц) и $E_{0}=216$ мкДж (1.67 и 5 кГц), что при длительности импульса $\tau=450$ фс и диаметре несфокусированного луча 2.6 мм дает для интенсивности излучения $I=5 \Gamma \mathrm{BT} / \mathrm{cm}^{2}$ в первом случае и $I=9.2 \Gamma \mathrm{\Gamma T} / \mathrm{cm}^{2}$ во втором. Сразу можно отметить, что зависимости коэффициента поглощения от интенсивности излучения в данном диапазоне интенсивности в экспериментах авторов не наблюдалось.

Для измерения мощности излучения лазера в импульсно-периодическом режиме использовался калориметрический измеритель средней мощности излучения Ophir Starlite 50A-BВ-26. Для измерения коэффициента поглощения жидкостей использовался набор метрологических прямоугольных кювет из кварцевого стекла оптического качества с калиброванной длиной пробега излучения в жидкости 5, 10, 20, 30 и 50 мм. Измерялась энергия импульса излучения до и после прохождения через кюветы с жидкостью. Коэффициент поглощения находился из зависимости логарифма отношения энергии импульса после прохождения кюветы к исходной $\ln \left(E_{w} / E_{0}\right)$ от толщины слоя жидкости $d$ по наклону прямой, интерполирующей данные измерения $\ln \left(E_{w} / E_{0}\right)=r_{a}+k_{a} d$, где $r_{a}$ - суммарный коэффициент отражения от стенок кюветы (примерно одинаковый для всех кювет), $k_{a}$ - искомый коэффициент поглощения, как показано на рис. 2.

Абсолютная точность измерения коэффициента поглощения, оцениваемая как $0.001 \mathrm{~cm}^{-1}$, не позволила уверенно измерить только коэффициент поглощения излучения в тетрахлорметилене, который, по измерениям других авторов [16], составляет $0.00055 \mathrm{~cm}^{-1}$. 
Полученные данные по измерению коэффициентов поглощения в исследуемых растворителях, а также оценки критической мощности самофокусировки и величины смещения фокуса вследствие самофокусировки, рассчитанные по формулам Приложения 2 для двух схем фокусировки (с параметрами фокусировки $f / 5 n$ и $f / 12.8 n$, где $n$ - коэффициент преломления жидкости), представлены в табл. 1. Следует отметить, что данные по поглощению излучения в жидкостях, полученные в данной работе, согласуются с данными работы [16], а также с другими справочными данными по спектральным коэффициентам поглощения ближнего инфракрасного излучения в жидкостях, например [1]. Это означает, в частности, что в рассматриваемом диапазоне интенсивностей механизмы поглощения излучения мало отличаются от механизмов поглощения при низких уровнях интенсивности.

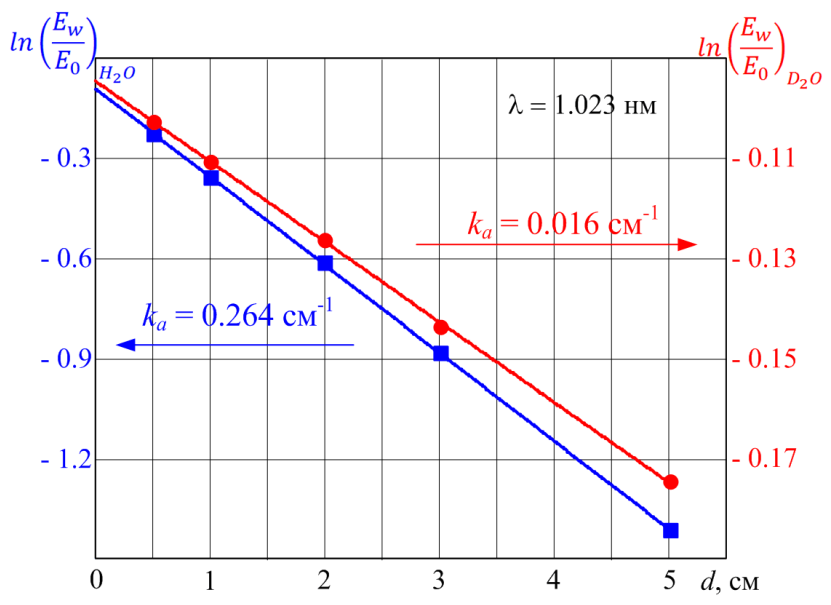

Рис. 2. Результаты измерения коэффициента поглощения излучения фемтосекундного лазера в обычной дистиллированной воде $\left(\mathrm{H}_{2} \mathrm{O}\right.$, синий цвет и квадраты) и тяжелой воде $\left(\mathrm{D}_{2} \mathrm{O}, 99.9 \%\right.$ - красный цвет и кружки). $E_{0}, E_{w}$ - энергия импульса до и после прохождения кюветы с поглощающей жидкостью; $\mathrm{d}$ - толщина слоя жидкости, точки - данные измерения, прямые - интерполяция данных

Также из табл. 1 видно, что за исключением обычной воды и спиртов, исследуемые жидкости имеют весьма небольшие коэффициенты поглощения (менее $0.05 \mathrm{~cm}^{-1}$ ), мало влияющие на процесс самофокусировки. В такой ситуации при оценке величины смещения фокуса при самофокусировке в большинстве случаев учитывалось только небольшое снижение мощности излучения за счет поглощения при его прохождении через нелинейную среду до точки самофокусировки.

Как следует из данных, представленных в табл. 1, в проведенных экспериментах критическая мощность самофокусировки в исследуемых жидкостях составляет от 1.5 до 4 МВт, превышение мощности излучения над критической от 55 до 310 раз. Согласно оценкам по формулам Приложения 2, сведенным в табл. 1, максимальное смещение фокуса $\left(z_{m}-z_{s f}\right)$ в оптической системе с линзой $f=13.2$ мм $(f / 5 n)$ в зависимости от сорта жидкости составляет от 0.45 до 1 мм, а в системе с линзой $f=33.3$ мм $(f / 12.8 n)$ - от 2.3 до 5.1 мм. Как показано ниже в разделе 3.3 данной работы, реально наблюдаемые величины смещения фокуса оказались примерно вдвое больше вычисленных по формуле (П2.4).

Последний столбец в табл. 1 представляет коэффициент нелинейной дисперсии $k_{2}$, характеризующий увеличение длительности импульса при прохождении нелинейной оптической среды. Имеющий размерность длины параметр $\tau^{2} / k_{2}$ дает оценку для характерной длины дисперсии при прохождении нелинейной среды, на которой длительность импульса $\tau$ возрастает вдвое [12]. Для рассматриваемых сред $k_{2}$ лежит в пределах $14 \div 55 \mathrm{\phi c}^{2} / \mathrm{Mм}$, то есть для $\tau=450$ фс и $d<50$ мм $\tau^{2} / k_{2} \gg d$ и изменением параметров импульса из-за дисперсии можно пренебречь. 


\section{Таблииа 1}

Свойства нелинейных оптических сред при воздействии импульсного лазерного излучения с длительностью импульса $\tau=450$ фс и мощностью в импульсе до 500 МВт $\left(\lambda=1.023\right.$ мкм; фокусировка линзами $f=13.2,33.3$ мм; луч с параметром распространения М ${ }^{2}=1.3$, диаметр на линзе $d=2.6$ мм)

\begin{tabular}{|c|c|c|c|c|c|c|c|}
\hline \multirow[t]{2}{*}{$\begin{array}{l}\text { Нелинейная } \\
\text { среда }\end{array}$} & \multirow{2}{*}{$\begin{array}{l}\text { Коэффициент } \\
\text { преломления, } n_{0} \\
\text { ([16] и др.) } \\
\lambda=1.023 \text { мкм }\end{array}$} & \multirow{2}{*}{$\begin{array}{c}\text { Коэффициент } \\
\text { поглощения, } \\
k_{a}, \mathrm{~cm}^{-1}([16], \\
\text { данная работа) }\end{array}$} & \multirow{2}{*}{$\begin{array}{c}\text { Нелинейный } \\
\text { коэффициент } \\
\text { преломления, } \\
n_{2} \times 10^{-20} \mathrm{M}^{2} / \mathrm{BT} \\
{[14,15]}\end{array}$} & \multirow{2}{*}{$\begin{array}{l}\text { Критическая } \\
\text { мощность само- } \\
\text { фокусировки } \\
P_{\text {сr, }} \text { МВт [12] }\end{array}$} & \multicolumn{2}{|c|}{$\begin{array}{c}\text { Нелинейное смещение фокуса } \\
\text { при } P_{6 \mathrm{x}}=0.5 \times 10^{9} \text { Вт, мм } \\
\text { (в скобках }\left(P / P_{\mathrm{cr}}\right), P=P_{\mathrm{BX}}-\text { потери) }\end{array}$} & \multirow{2}{*}{$\begin{array}{c}\text { Нелинейная } \\
\text { добавка к дис- } \\
\text { персии, } \\
k_{2}, \phi c^{2} / \mathrm{Mм}[17]\end{array}$} \\
\hline & & & & & Линза $f=13.2$ мм & Линза $f=33.3$ мм & \\
\hline Тяжелая вода & 1.322 & 0.016 & 3.3 & 3.8 & $0.54(115)$ & $3.1(112)$ & --- \\
\hline Этанол & 1.355 & 0.153 & 4 & 3 & $0.58(124)$ & $3.1(99)$ & --- \\
\hline Дихлорметан & 1.420 & 0.04 & 6.5 & 1.8 & $0.88(238)$ & $4.8(227)$ & --- \\
\hline Хлороформ & 1.436 & 0.0051 & 8 & 1.5 & $1.0(310)$ & $5.6(310)$ & --- \\
\hline Тетрахлорметан & 1.451 & $0.00055[16]$ & 6 & 1.9 & $0.92(240)$ & $5.1(240)$ & 53.3 \\
\hline Кварц & 1.45 & - & 3 & 3.8 & - & - & - \\
\hline
\end{tabular}




\section{3. Результаты эксперимента}

\section{1. Осевые и поперечные потоки при слабой самофокусировке}

В экспериментах при минимальной энергии импульса (с учетом потерь в оптическом тракте $E_{p} \approx 10$ мкДж, $P \leq 20 P_{\text {cr }}$ ) при частоте повторения импульсов 1.67 кГц и 5 кГц наблюдался квазистационарный поток жидкости, вытекающий из области фокальной перетяжки в обе стороны вдоль лазерного луча, а также в направлении, перпендикулярном лазерному лучу (рис. 3). Поток вдоль лазерного луча наблюдался в том случае, когда лазерный луч фокусировался точно на оптической оси линзы без астигматизма (рис. $3, a, c$ ). Для внесения искусственного астигматизма центр линзы с фокусным расстоянием $f=13.2$ мм (параметр фокусировки $f / 5 n$ в среде с коэффициентом преломления $n$ ) смещался поперек оси луча на $0.7 \div 1$ мм, одновременно линза наклонялась на угол $1.5 \div 2.2$ градусов.

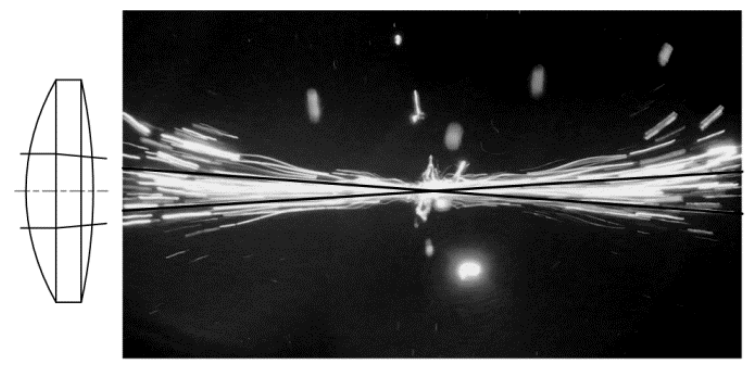

a)

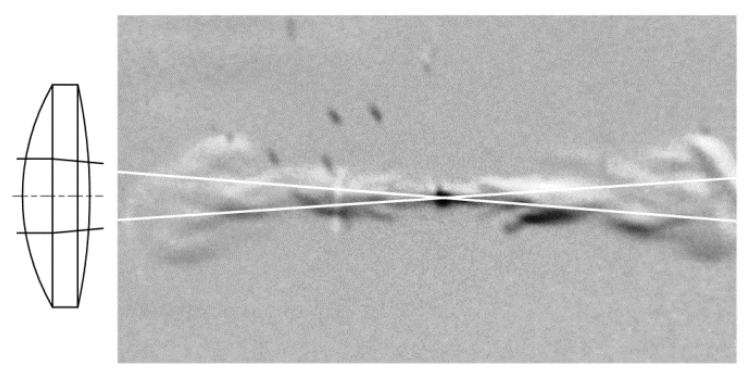

c)

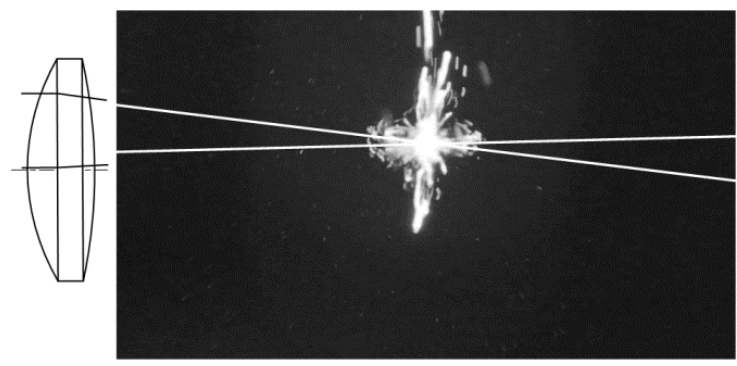

b)

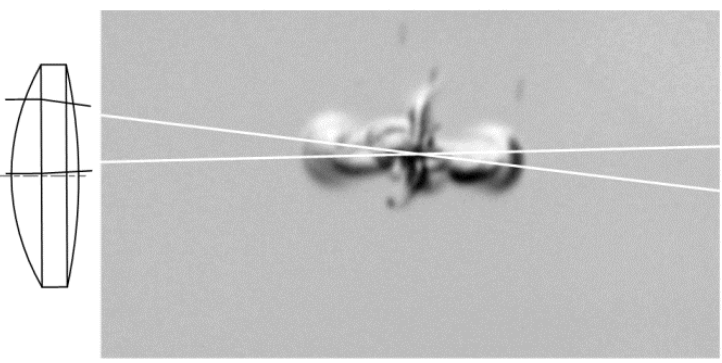

d)

Рис. 3. Схема образования потоков в случае слабой самофокусировки при точной фокусировке $a), c$ ) и внесенном астигматизме $b), d$ ). Потоки визуализированы с помощью подсвеченных газовых пузырьков $a), b$ ) и теневым методом $c), d$ ). Фокусировка $f / 5 n$, где $n-$ коэффициент преломления жидкости; линии показывают границы луча. Энергия в импульсе $E \leq 20$ мкДж $\left(P<10 P_{\text {cr }}\right)$, частота $v_{r}=5$ кГц. Излучение падает слева направо. Жидкость: $a), b$ ) вода, $n=1.325 ; c), d)$ - тетрахлорметан, $n=1.45$. Размер кадра $a), b$ ) $\left.\left.3.8 \times 2.1 \mathrm{mм}^{2}, c\right), d\right) 19.6 \times 11 \mathrm{мм}^{2}$. Положение фокусирующей линзы показано схематически

Согласно расчетам Приложения 1 фокальная перетяжка при этом разделялась на два астигматических фокуса, расположенных на расстоянии $a=0.5 \div 1$ мм друг от друга по оси луча. При характерной длине перетяжки $<0.25$ мм такое значение величины $a$ означало, что фокусы отчетливо разделялись. В этом случае поток вдоль оптической оси ослабевал, и наблюдалось появление потока жидкости в перпендикулярном направлении. При анализе кадров видеосъемки видно, что в каждом из астигматических фокусов генерируется ослабленный осевой поток, а эффект поперечного растекания возникает в результате столкновения встречных осевых потоков из разных фокусов. При возвращении линзы в положение точной настройки растекание в стороны прекращалось, а поток вдоль оси усиливался. Наблюдаемые скорости перемещения воздушных пузырьков в среднем сечении струи в положении точной настройки были до десяти сантиметров в секунду, что указывало на возможную скорость в минимальном сечении у фокуса до метра в секунду или более. 
Скорость определялась по длине треков от движущихся пузырьков, как на рис. 3, a), при известном времени экспозиции.

\section{2. Осевые и поперечные потоки при доминирующем влиянии самофокусировки}

В случае, когда энергия в импульсе с учетом потерь в оптической системе составляла 100 мкДж и более $\left(P \geq 100 P_{\mathrm{cr}}\right)$, наблюдалась более сложная картина течений, обусловленная тем, что в жидкости при достаточно большой интенсивности излучения проявлялся эффект самофокусировки (керровская линза), и не доходя до обычного фокуса луч сжимался в перетяжку. В области перетяжки происходит взаимодействие усилившегося поля световой волны с электронами молекул жидкости, вызывающее диссоциацию и одновременно дефокусировку луча. Этот процесс повторяется несколько раз, пока луч, теряя мощность изза поглощения, не перестает самофокусироваться. Данные по поглощению мощности лазерного излучения в филаменте приведены в табл. 2 раздела 3.3.

В результате образуется несколько перетяжек, в каждой из которых жидкость приходит в движение по оси луча, а между ними продольные потоки сталкиваются и растекаются в поперечном направлении. На рис. 4 показано в динамике формирование картины течений после включения излучения с частотой повторения импульсов 1.67 кГц, а также установившаяся картина продольных и поперечных течений при частоте повторения 5 кГц. Энергия в импульсе в обоих случаях 200 мкДж (с учетом потерь в системе подвода и фокусировки излучения). Особенностью режима с большой энергией в импульсе и высокой частотой повторения является нагрев жидкости вдоль пути луча из-за обычного поглощения, вызывающий локальное изменение диэлектрических коэффициентов по мере нагрева. Поэтому положение филаментов, образующихся из-за самофокусировки, меняется: они максимально растянуты вдоль оси луча в начальный момент, когда нагрев мал, а по мере нагрева сближаются, в результате чего при наблюдении потоков становится сложно их визуально разделить. Соответственно, в установившемся режиме картина потоков выглядит как два продольных потока, движущихся по каналу луча навстречу друг другу и растекающихся в стороны в месте столкновения. Тепло, выделяющееся вследствие поглощения лазерного излучения, в основном, в области перетяжек, переносится этими потоками к месту их столкновения, где после растекания жидкости в стороны образуется факел термогравитационной конвекции, уносящий выделяющееся тепло в верхние слои жидкости. На установившейся картине течений с меньшей частотой следования импульсов и, соответственно, меньшим энерговыделением еще можно разделить несколько точек растекания потоков в стороны, также сливающиеся затем в единый конвективный факел. При более высокой частоте повторения течение в области растекания сильно турбулентно и отдельные точки растекания сближаются настолько, что их уже невозможно различить.

\section{3. Смещение фокуса в результате самофокусировки и поглощение в филаменте}

В табл. 2 приведены измеренные значения различных параметров лазерного излучения в области самофокусировки (филаментации). Измерения проводились в различных жидкостях с различными частотами повторения импульсов $v_{r}$, энергией в импульсе перед фокусирующей линзой $E_{p}$, энергией в импульсе на входе в область филаментации $E_{s f}$. Поглощенная энергия $E_{a}$ вычислялась как разница измеренных энергий на входе и выходе системы линза-кювета-жидкость (см. рис. 1) с учетом отражения излучения от поверхностей раздела и поглощения в жидкости. Оценочная величина интенсивности лазерного излучения в области перетяжки $I_{f}=E_{s f} /\left(\tau \pi w_{0}^{2}\right)$, где $\tau$ - длительность импульса, а $w_{0}$ - радиус луча в перетяжке в отсутствие самофокусировки, приведена для справок. Как видно из последней колонки табл. 2 , доля излучения, поглощенного в области филамента, $E_{a} / E_{s f}$ достаточно велика, и составляет в зависимости от рода жидкости, энергии в импульсе и параметра фокусировки от 35 до $80 \%$. 


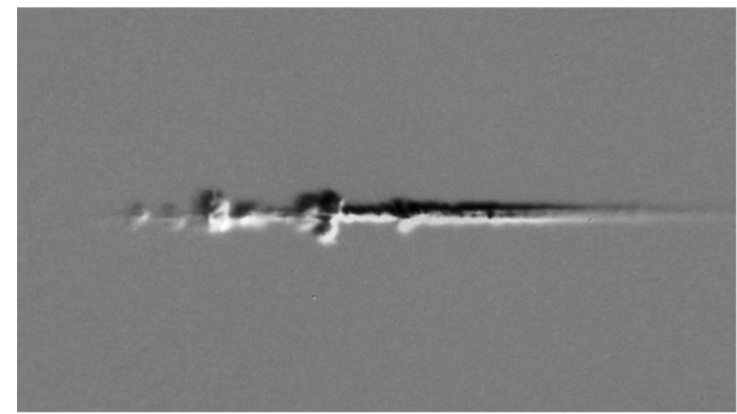

1.7 кГц, 50 мс

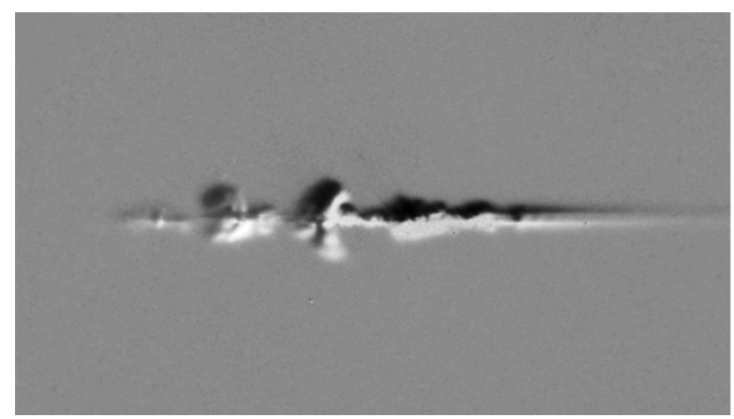

1.7 кГц,110 мс

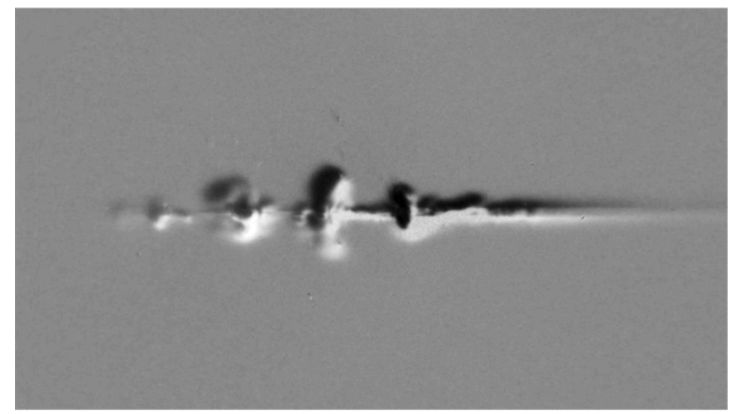

1.7 кГц, $150 \mathrm{Mc}$

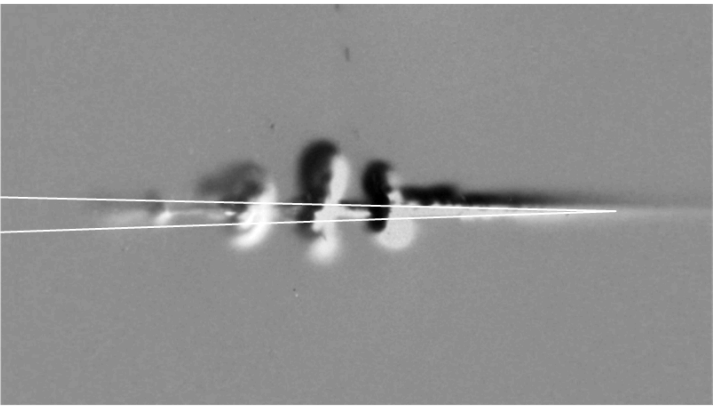

1.7 кГц, $0.25 \mathrm{c}$

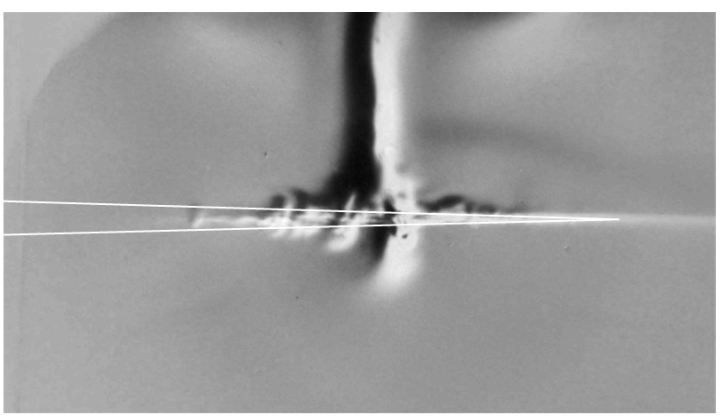

1.7 кГц, $2.3 \mathrm{c}$

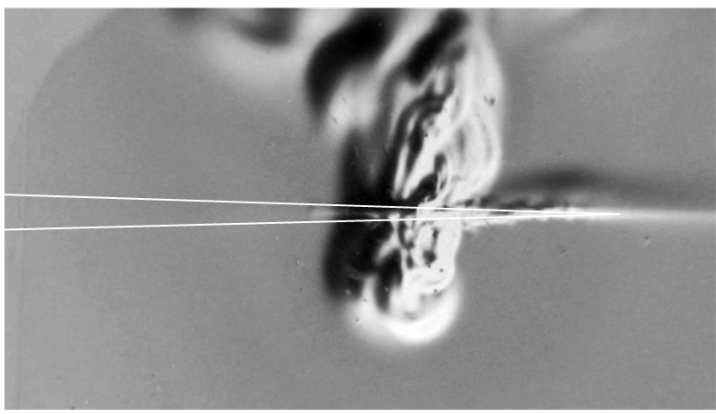

5 кГц, установившийся режим

Рис. 4. Образование продольных и поперечных потоков в тетрахлорметане под действием излучения импульсно-периодического лазера при наличии нескольких перетяжек, образующихся в результате самофокусировки. Метки времени - от момента включения излучения. Энергия в импульсе $E_{s f} \approx 200$ мкДж, параметр фокусировки $f / 12.8 n, n=1.45$, линиями показана граница луча в отсутствие самофокусировки. Излучение падает слева направо. Размер кадра $19.6 \times 11$ мм² $^{2}$

От рода жидкости и других параметров зависела также длина и положение начала филамента относительно точки фокуса лазерного излучения, каким оно было бы в отсутствие самофокусировки. На рис. 5 показаны фотографии филаментов, полученных в тяжелой воде при различной энергии импульса лазерного излучения. Филаменты визуализировались в результате накопления пузырьков диссоциированной воды за время от нескольких миллисекунд до нескольких десятков миллисекунд в зависимости от частоты кадров при видеосъемке. Пузырьки подсвечивались лазерным излучением, развернутым в линию и сфокусированным в виде «светового листа». На рис. $5, d$ ) показан кадр видеосъемки установившегося режима $v_{r}=3.3$ кГц, $E_{p}=125$ мкДж, при котором движение пузырьков газа визуализирует поток жидкости вокруг филамента, вызванный лазерным воздействием.

В табл. 3 приведены измеренные длины филаментов $l_{s f}$ и величины смещения точки начала филамента $z_{s f}-z_{s f}$ при увеличении энергии в импульсе и частоты следования импульсов в различных жидкостях. Смещение точки начала филамента $z_{s f}-z_{s f} f^{\prime}$ определялось по отношению к положению точки начала филамента $z_{s f}{ }^{\prime}$, соответствующей минимальной в данном эксперименте энергии в импульсе. 
Таблица 2. Поглощенная энергия лазерного излучения $E_{a}$ и другие параметры в области самофокусировки

\begin{tabular}{|c|c|c|c|c|c|c|}
\hline Среда & $V_{r}, \kappa \Gamma \amalg$ & $E_{\mathrm{p}}$, мкДжк & $E_{\mathrm{sf}}, \mathrm{MK} Д ж$ & $I_{\mathrm{f}}, 10^{14} \mathrm{BT} / \mathrm{cm}^{2}$ & $E_{a}$, мкДж & $\overline{E_{a} / E_{\mathrm{sf}}}$ \\
\hline \multirow{4}{*}{$\begin{array}{l}\text { Вода } \\
\text { Линза } \\
f=13.2 \text { мм, } \\
\text { кювета } 30 \text { мм }\end{array}$} & 5 & 10.4 & 6.9 & 0.19 & 3.9 & 0.57 \\
\hline & 1.43 & 117 & 77 & 2.2 & 56 & 0.72 \\
\hline & 5 & 216 & 142 & 4 & 106 & 0.74 \\
\hline & 10 & 118 & 78 & 2.2 & 59 & 0.76 \\
\hline \multirow{6}{*}{$\begin{array}{l}\text { Тяжелая вода } \\
\text { Линза } \\
f=33.3 \text { мм, } \\
\text { кювета } 50 \text { мм }\end{array}$} & 1.67 & 21.6 & 18.6 & 0.13 & 10 & 0.54 \\
\hline & 5 & 21.2 & 18 & 0.13 & 10 & 0.55 \\
\hline & 1.67 & 217 & 187 & 1.3 & 119 & 0.64 \\
\hline & 3.33 & 125 & 107 & 0.76 & 66 & 0.62 \\
\hline & 5 & 216 & 185 & 1.3 & 130 & 0.7 \\
\hline & 10 & 118 & 101 & 0.72 & 70 & 0.69 \\
\hline \multirow{3}{*}{$\begin{array}{l}\text { Пропанол } \\
f=13.2 \text { мм, } \\
\text { кювета } 30 \text { мм }\end{array}$} & 1.43 & 117 & 93 & 2.6 & 67 & 0.72 \\
\hline & 3.33 & 125 & 98 & 2.7 & 77 & 0.79 \\
\hline & 5 & 216 & 170 & 4.8 & 128 & 0.75 \\
\hline \multirow{5}{*}{$\begin{array}{l}\text { Ацетон } \\
\text { Линза } \\
f=33.3 \text { мм, } \\
\text { кювета } 50 \text { мм }\end{array}$} & 5 & 10.4 & 8.6 & 0.06 & 3 & 0.35 \\
\hline & 1.43 & 117 & 97 & 0.7 & 53 & 0.54 \\
\hline & 3.33 & 125 & 103 & 0.7 & 60 & 0.58 \\
\hline & 5 & 216 & 178 & 1.25 & 91 & 0.51 \\
\hline & 10 & 118 & 98 & 0.7 & 50 & 0.51 \\
\hline \multirow{5}{*}{$\begin{array}{l}\text { Дихлорметан } \\
\text { Линза } \\
f=33.3 \text { мм, } \\
\text { кювета } 50 \text { мм }\end{array}$} & 5 & 10.4 & 8.5 & 0.06 & 3 & 0.35 \\
\hline & 1.43 & 117 & 96 & 0.7 & 43 & 0.45 \\
\hline & 3.33 & 125 & 102 & 0.7 & 47 & 0.46 \\
\hline & 5 & 216 & 176 & 1.2 & 76 & 0.43 \\
\hline & 10 & 118 & 96 & 0.7 & 42 & 0.44 \\
\hline \multirow{3}{*}{$\begin{array}{l}\text { Хлороформ } \\
f=33.3 \text { мм, } \\
\text { кювета } 50 \text { мм }\end{array}$} & 3.33 & 125 & 112 & 0.8 & 57 & 0.51 \\
\hline & 5 & 216 & 194 & 1.4 & 98 & 0.51 \\
\hline & 10 & 118 & 106 & 0.74 & 55 & 0.52 \\
\hline \multirow{5}{*}{$\begin{array}{l}\text { Тетрахлорметан } \\
\text { Линза } \\
f=33.3 \text { мм, } \\
\text { кювета } 50 \text { мм }\end{array}$} & 5 & 10.4 & 9.6 & 0.07 & 4.3 & 0.45 \\
\hline & 1.66 & 217 & 199 & 1.4 & 82 & 0.41 \\
\hline & 3.33 & 125 & 115 & 0.8 & 49 & 0.43 \\
\hline & 5 & 216 & 198 & 1.4 & 90 & 0.45 \\
\hline & 10 & 118 & 108 & 0.76 & 50 & 0.46 \\
\hline
\end{tabular}

Таблица 3. Видимая длина филамента $l_{s f}$ и сдвиг начала области самофокусировки $z_{s f}-z_{s f}{ }^{\prime}$

\begin{tabular}{|c|c|c|c|c|c|c|}
\hline Среда & $v_{\mathrm{v},} \boldsymbol{\kappa} \Gamma_{ц}$ & $E_{\mathrm{p},}$, мкДж & $E_{\mathrm{sf},}$ МाкДжк & $I_{\mathrm{f}}, 10^{14} \mathrm{BT} / \mathrm{cm}^{2}$ & $l_{\mathrm{sf}}, \mathrm{MM}$ & $z_{\mathrm{sf}}-z_{\mathrm{sf}}{ }^{\prime}, \mathrm{MM}$ \\
\hline \multirow{3}{*}{$\begin{array}{l}\text { Тяжелая вода } \\
f=33.3 \text { мм, } \\
\text { кювета } 50 \text { мм }\end{array}$} & 5 & 20 & 17 & 0.12 & 1.7 & 0 \\
\hline & 3.33 & 125 & 107 & 0.75 & 6.3 & 4.4 \\
\hline & 5 & 215 & 184 & 1.3 & 6.5 & 4.5 \\
\hline \multirow{3}{*}{$\begin{array}{l}\text { Ацетон } \\
f=33.3 \text { мм, } \\
\text { кювета } 50 \text { мм }\end{array}$} & 5 & 10.4 & 8.6 & 0.06 & 3.7 & $\mathbf{0}$ \\
\hline & 3.33 & 125 & 103 & 0.7 & 12 & 7.4 \\
\hline & 5 & 216 & 178 & 1.25 & 12 & 7.3 \\
\hline \multirow{3}{*}{$\begin{array}{l}\text { Дихлорметан } \\
f=33.3 \text { мм, } \\
\text { кювета } 50 \text { мм }\end{array}$} & 5 & 10.4 & 8.5 & 0.06 & 5.6 & 0 \\
\hline & 3.33 & 125 & 102 & 0.7 & 13 & 8.4 \\
\hline & 5 & 216 & 176 & 1.2 & 13 & 8.3 \\
\hline \multirow{3}{*}{$\begin{array}{l}\text { Хлороформ } \\
f=33.3 \text { мм, } \\
\text { кювета } 50 \text { мм }\end{array}$} & 5 & 10.5 & 9.4 & 0.07 & 6.5 & $\mathbf{0}$ \\
\hline & 3.33 & 125 & 112 & 1.4 & 13.8 & 8.6 \\
\hline & 5 & 216 & 194 & 0.74 & 14.2 & 8.6 \\
\hline \multirow{3}{*}{$\begin{array}{l}\text { Тетрахлорметан } \\
f=33.3 \text { мм, } \\
\text { кювета } 50 \text { мм }\end{array}$} & 5 & 10.4 & 9.6 & 0.07 & 4.4 & 0 \\
\hline & 3.33 & 125 & 115 & 1.4 & 10.3 & 6.8 \\
\hline & 5 & 216 & 198 & 0.76 & 10.6 & 6.9 \\
\hline
\end{tabular}


При увеличении энергии в импульсе самофокусировка наступала раньше, и длина и смещение точки начала увеличивалась. С ростом частоты повторения импульсов проявлялась обратная тенденция, по-видимому, в результате теплового эффекта, изменявшего линейный коэффициент преломления в области, занятой лучом. Поэтому при переходе от режима $v_{r}=3.33$ кГц, $E_{p}=125$ мкДж к $v_{r}=5$ кГц, $E_{p}=216$ мкДж длина филамента и смещение точки начала менялись мало.

Следует отметить, что измеренные величины смещения точки начала филамента для всех жидкостей примерно вдвое превосходят соответствующие величины, вычисленные по формуле (П2.4) (табл. 1), что, по-видимому, обусловлено заниженной оценкой при использовании для мощности фемтосекундного импульса соотношения $P=E_{p} / \tau$, а для интенсивности $-I=P /\left(\pi w^{2}\right)$, где $w-$ радиус луча. Для уточнения оценки нужно знать конкретную форму импульса и распределение интенсивности по сечению луча на входе в нелинейную оптическую среду.

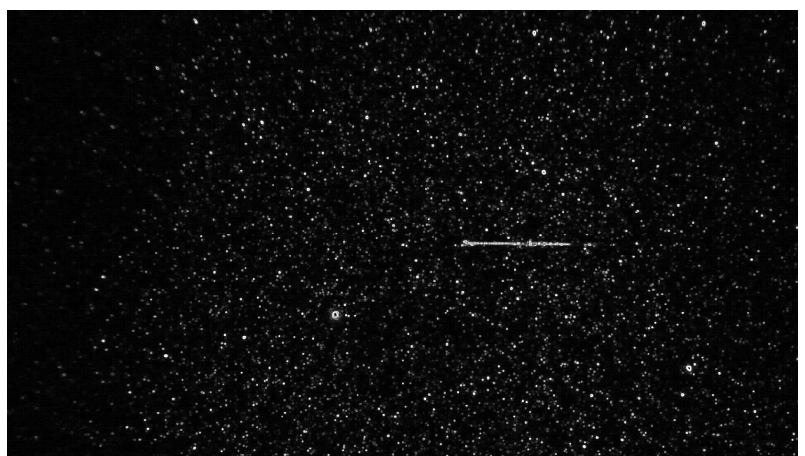

a)

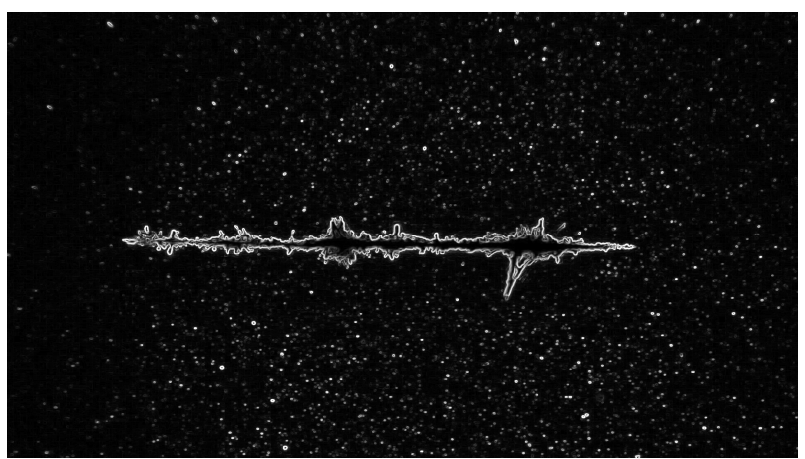

c)

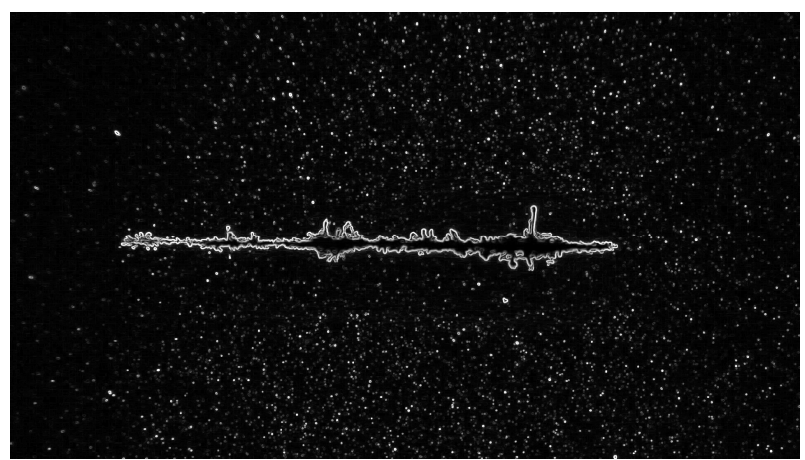

b)

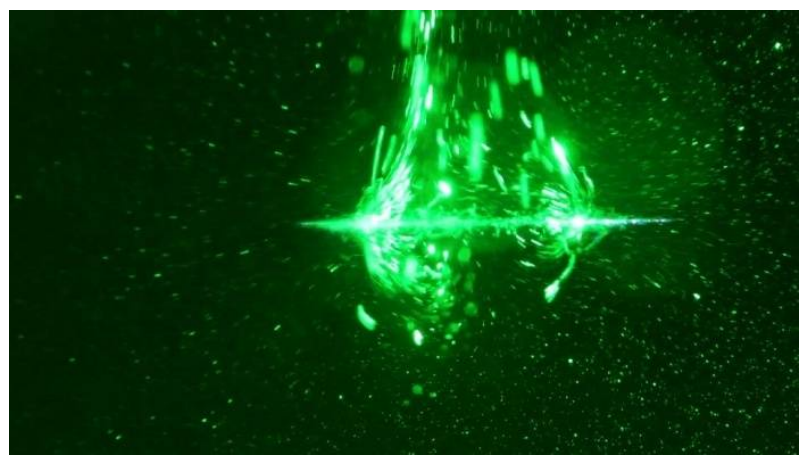

d)

Рис. 5. Филаментация излучения фемтосекундного лазера в результате самофокусировки в тяжелой воде. Параметр фокусировки $f / 17$, излучение подводится слева. $a)-c$ ) Филамент визуализирован подсвеченными лазерным листом пузырьками диссоциированной жидкости, контур филамента выделен при компьютерной обработке изображения. Размер кадра $10 \times 5.6 \mathrm{mм}^{2} . a$ ) частота $v_{r}=5$ кГц, энергия в импульсе $E_{p}=21$ мкДж; $\left.b\right) v_{r}=3.33$ кГц, $E_{p}=125$ мкДж; $\left.c\right) v_{r}=5$ кГц, $E_{p}=216$ мкДж; d) кадр видеосъемки установившегося режима $v_{r}=3.3$ кГц, $E_{p}=125$ мкДж, экспозиция 30 мс

\section{5. Заключение и выводы}

При взаимодействии с жидкостями сфокусированного излучения импульсно-периодического фемтосекундного лазера при мощности излучения $P \approx(10 \div 20) P_{\text {cr }}$, где $P_{\text {cr }}-$ критическая мощность самофокусировки излучения в жидкости, в области фокальной перетяжки образуются квазистационарные потоки, направленные вдоль оси лазерного луча в обе стороны от перетяжки. В случае, когда перетяжек несколько, например, при фокусировке с астигматизмом (2 перетяжки) или при $P \geq 100 P_{\mathrm{cr}}$, когда фокальная перетяжка формируется 
за счет самофокусировки (филаментации) мощного импульсного излучения с возникновением нескольких областей самофокусировки-дефокусировки, наряду с потоками вдоль луча наблюдаются участки с растекающимся в стороны от луча потоком. При этом встречные продольные потоки, генерируемые в перетяжках с высокой интенсивностью лазерного излучения, разделенных промежутками дефокусированного луча, сталкиваются в этих промежутках и растекаются в стороны, формируя течение в направлении, перпендикулярном лазерному лучу. При высокой частоте повторения импульсов и значительном тепловыделении в области самофокусировки продольные потоки переносят выделяющееся тепло вдоль луча к точке поперечного растекания потоков, от которой формируется единый поток термогравитационной конвекции, аккумулирующий выделяющееся в зоне самофокусировки тепло.

В экспериментах была реализована возможность изменения формы и расположения зон энерговыделения при лазерном воздействии в жидкости с помощью регулируемой степени астигматизма за счет изменения положения фокусирующей линзы с относительно оси лазерного луча. Было показано, что конвективные потоки в области фокальной перетяжки, наблюдаемые теневым методом или методом подсветки газовых пузырьков развернутым в лист излучением вспомогательного лазера видимого диапазона, в зависимости от степени астигматизма могли быть направлены строго вдоль оси лазерного луча и/или в поперечном направлении. При значительном превышении мощности лазерного излучения над критической для самофокусировки, когда длина области самофокусировки, прилегающая к фокальной перетяжке, превышала 1 мм, наблюдались как потоки вдоль оси лазерного луча, по направлению от краев области самофокусировки к ее центру, так и в перпендикулярном лазерному лучу направлении. Поперечные потоки формировались в результате столкновения направленных навстречу друг другу осевых потоков.

Поскольку общая картина течений во всех исследованных жидкостях была сходной, авторы данной работы считают динамический механизм образования потоков в результате коллапса фотодиссоционных газовых пузырьков наиболее вероятным механизмом, ответственным за образование наблюдаемых потоков. Механизм пондеромоторной конвекции, подробно описанный в работе [18] для случая воздействия непрерывного лазера на жидкость, или конвекции в результате генерации ультразвуковых волн посредством наночастиц, находящихся в плазмонном резонансе с лазерным излучением [19], не объясняют всей совокупности наблюдаемых в данной работе явлений.

Результаты проведенных исследований могут служить основой для применения в лазерных технологиях обработки или синтеза материалов с применением жидкостной среды. Требуются дальнейшие исследования конкретных механизмов и возможностей применения обнаруженных явлений.

\section{Приложение 1}

\section{Расчет астигматизма, вносимого при смещении фокусирующей линзы}

Для расчета величины искусственного астигматизма, создаваемого путем смещения и наклона линзы относительно оси лазерного излучения, использовались методы программного пакета многолучевой оптики Zemax. Пример такого расчета показан на рис. П1.1.

В экспериментах смещение и наклон линзы с фокусным расстоянием $f=13.2$ мм (параметр фокусировки $f / 5 n$ в среде с коэффициентом преломления $n$ ) относительно оси лазерного луча могли меняться в пределах $0.7 \div 1$ мм (смещение) и $1.5 \div 2.2$ градуса (угол наклона). Расчеты показали, что при этом фокальная перетяжка распадалась на два астигматических фокуса, расстояние между которыми менялось в пределах $a=0.5 \div 1$ мм друг от друга по оси луча с учетом его отклонения. При характерной длине перетяжки $<0.25$ мм такая величина а означала, что астигматические фокусы при таком смещении и наклоне линзы отчетливо разделялись. 


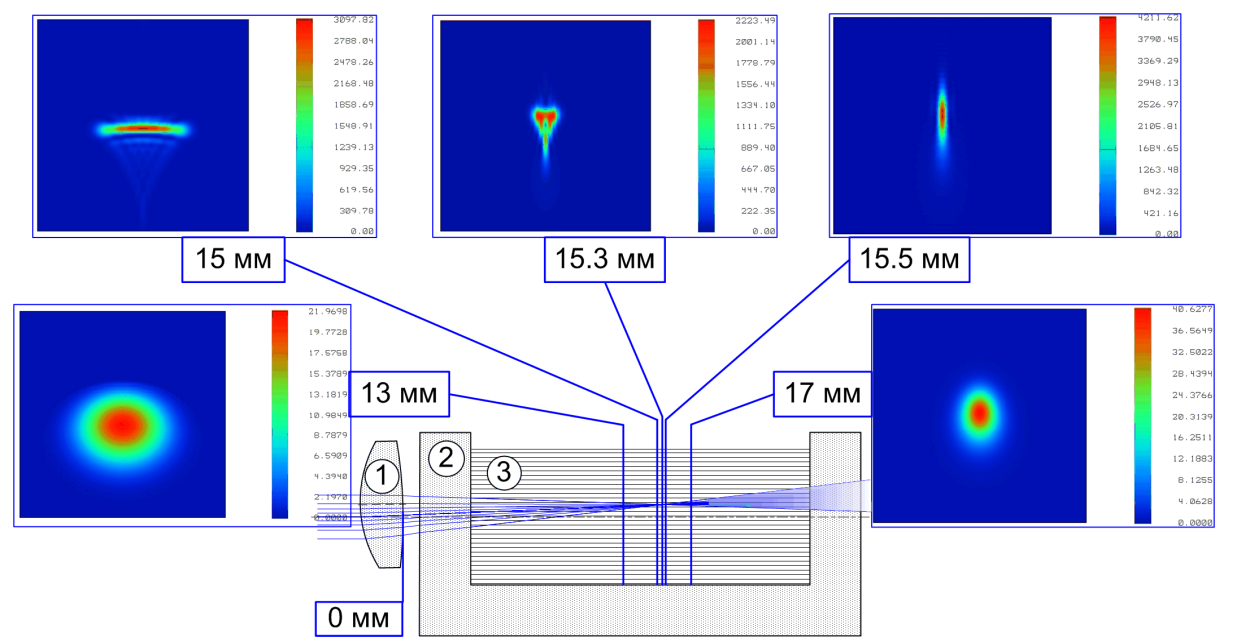

Рис. П1.1. Пример расчета распределений интенсивности в поперечных сечениях астигматического лазерного луча в области фокальных перетяжек методом многолучевой оптики. На врезках вверху условными цветами показаны распределения интенсивности излучения в различных сечениях лазерного луча вблизи фокусов, возникающие при смещении линзы 1 с фокусным расстоянием $f=13.2$ мм на 0.7 мм вверх от оси лазерного излучения и наклона на 1.6 градуса, как это происходило в реальном эксперименте. 2 - кварцевая кювета длиной 20 мм, 3 - жидкость $n=1.325$ (вода). Показаны распределения интенсивности (слева по часовой стрелке) на расстоянии 13 мм от поверхности линзы (2 мм до первого астигматического фокуса), 15 мм - первый фокус, 15.3 мм - середина между фокусами, 15.5 мм - второй фокус, 17 мм - 2 мм после первого фокуса

\section{Приложение 2}

\section{Оценка влияния самофокусировки}

Эффект самофокусировки при распространении лазерного излучения высокой мощности в среде с коэффициентом преломления $n_{0}$ обусловлен зависящей от интенсивности нелинейной добавкой $n_{2} I$, так что результирующий коэффициент преломления $n(I)=n_{0}+n_{2} I$. Для многих жидкостей, в том числе растворителей, использовавшихся в экспериментах, с характерной величиной размерного коэффициента $n_{2} \sim 10^{-19} \mathrm{M}^{2} / \mathrm{BT}$, самофокусировка становится существенной в диапазоне мощности излучения $10^{6} \div 10^{8}$ Вт.

Согласно [12] вследствие самофокусировки луч с плоским волновым фронтом после вхождения в нелинейную среду стремится коллапсировать с характерным углом самофокусировки $\theta_{s f}=\left(2 n_{2} I / n_{0}\right)^{1 / 2}$ (угол $\theta_{s f}$ показан на рис. П2.1).

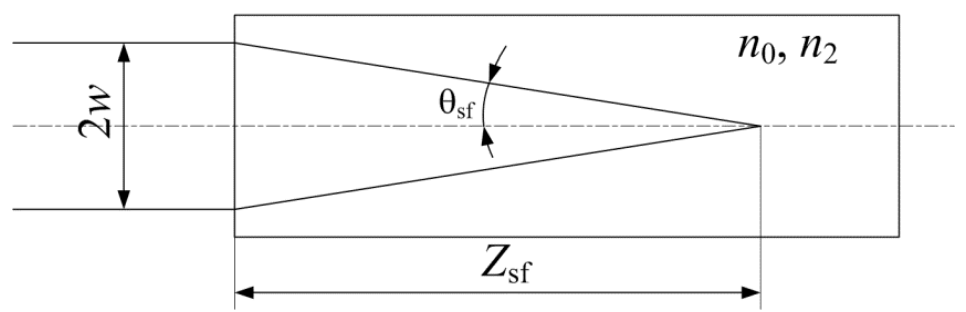

Рис. П2.1. Самофокусировка лазерного луча с плоским волновым фронтом в нелинейной среде с коэффициентом преломления, зависящим от интенсивности по закону $n=n_{0}+n_{2} I$

Это соотношение выводится из принципа Ферма, согласно которому оптическая длина пути по оси луча, где $n=n_{0}+n_{2} I$, и по периферии, где $n \approx n_{0}$, от плоскости вхождения луча до точки фокуса должна быть одинакова. Самофокусировке луча препятствует дифракция, 
из-за которой лазерный луч становится расходящимся. Характерный угол дифракции для гауссова пучка $\left(I(r)=I_{0} \exp \left(-2(r / w)^{2}\right)\right) \theta_{d i f}=\lambda^{2} /\left(\pi w n_{0}\right)$, где $\lambda$ - длина волны лазерного излучения, $w$ - радиус луча на входе в нелинейную среду (см. рис. П2.1). Из условия компенсации дифракционной расходимости за счет самофокусировки $\theta_{s f}=\theta_{d i f}$ получаем выражение для критической интенсивности и из него для пороговой (критической) мощности самофокусировки (эта величина не зависит от диаметра луча) $P_{\mathrm{cr}}=\alpha \lambda^{2} /\left(4 \pi n_{0} n_{2}\right)$. Коэффициент $\alpha$ зависит от распределения интенсивности в луче и принимает минимальное значение $\alpha=1.86$ для распределения, называемого солитоном Таунса. Для гауссова распределения [13] $\alpha=1.9$, для супергауссова $\left(I(r) \sim \exp \left(-2(r / w)^{4}\right)\right) \alpha=2$. В нашем случае луча с распределением интенсивности, близким к гауссовскому, но с меньшей интенсивностью на оси (параметр распространения $\mathrm{M}^{2}=1.3$ ), можно принять $\alpha=2$. Таким образом

$$
P_{\text {cr }}=\frac{\lambda^{2}}{2 \pi n_{0} n_{2}}
$$

Соотношение (П2.1) справедливо для непрерывного излучения. В случае импульсного излучения необходимо решать нелинейное дифференциальное уравнение распространения излучения в нелинейной среде, однако для оценок и в этом случае можно использовать выражение (П2.1) [12], если учитывать зависимость нелинейной добавки коэффициента преломления $n_{2}$ от длительности импульса.

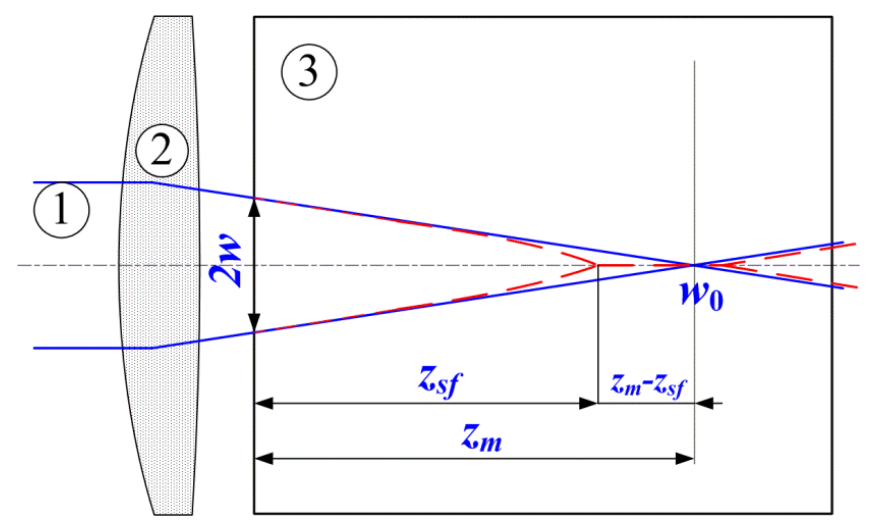

Рис. П2.2. Эффект самофокусировки в сфокусированном лазерном луче. 1 - лазерный луч; 2 - фокусирующая линза, 3 - нелинейная среда $n(I)=n_{0}+n_{2} I$

Систематизированные данные по зависимости $n_{2}$ от длительности импульса для исследуемых жидкостей можно найти, например, в $[14,15]$.

Для $Z_{s f}$, как на рисунке, при мощности излучения $P>P_{\text {cr }}$ справедливо соотношение

$$
Z_{s f}=\frac{2 n_{0} w_{0}^{2}}{\lambda} \frac{1}{\sqrt{P / P_{\mathrm{cr}}-1}}
$$

В нашем эксперименте при $P>P_{\text {cr }}$ одновременно действуют фокусирующая линза оптической системы с фокусным расстоянием $f$ и нелинейная линза в среде, характеризующаяся длиной самофокусировки $Z_{s f}$.

Самофокусировка приведет к тому, что излучение сфокусируется в среде на меньшей длине $z_{s f}$, не доходя до линейного фокуса $z_{m}$, как показано на рис. П2.2. Для вычисления $z_{s f}$ складываем оптические силы обычной и нелинейной линз 


$$
\frac{1}{z_{s f}}=\frac{1}{Z_{s f}}+\frac{1}{f},
$$

откуда для $z_{s f}$ (рис. П2.2) в случае лазерного луча, характеризующегося параметром распространения $\mathrm{M}^{2} \geq 1$ получаем, модифицируя соответствующее соотношение из [12] с учетом параметра распространения $\mathrm{M}^{2}$ :

$$
z_{s f}=\frac{k w^{2} / 2 \mathrm{M}^{2}}{\sqrt{\frac{P}{P_{\mathrm{cr}}}-1}+\frac{2 z_{m} M^{2}}{k w_{0}^{2}}},
$$

где $k=2 n_{0} \pi / \lambda, w_{0}=2 z_{m} \mathrm{M}^{2} / k w ; w$ - диаметр луча на входе в нелинейную среду; $w_{0}-$ диаметр луча, каким он был бы в перетяжке в отсутствие нелинейности; $z_{m}$ - соответствующая координата точки фокуса в отсутствие нелинейной самофокусировки, например, при $P<P_{\text {cr }}$. Обозначения в формуле (П2.4) соответствуют рис. П2.2.

\section{Благодарности и ссылки на гранты}

Работа выполнена частично по теме государственного задания (№ гос.рег. АAАAА17-117021310370-2) и проекта РФФИ 18-01-00534 А.

\section{Литература}

1. Kruusing A. Handbook of Liquids-Assisted Laser Processing. Elsevier Science, 2010. 464 p.

2. Hoppius J.S., Maragkaki S., Kanitz A., Gregorčič P., Gurevich E.L. Optimization of femtosecond laser processing in liquids // Applied Surface Science, 2019, pp. 467-468, 255-260.

3. Simakin, A.V., Voronov, V.V., Kirichenko, N.A., Shafeev, G.A. Nanoparticles produced by laser ablation of solids in liquid environment // Applied Physics A: Materials Science and Processing, 2004, 79(4-6), pp. 1127-1132.

4. Nee C.-H., Yap S.-L., Tou T.-Y., Chang H.-C., Yap S.-S. Direct synthesis of nanodiamonds by femtosecond laser irradiation of ethanol // Scientific Reports, 2016, 6, 33966.

5. Иногамов Н.А., Жаховский В.В., Хохлов В.А., Хищенко К.В., Петров Ю.В., Ильницкий Д.К., Мигдал К.П. Роль геометрических параметров при фемтосекундной лазерной абляции // Физико-химическая кинетика в газовой динамике. 2014. Т.15, вып.5.

http://chemphys.edu.ru/issues/2014-15-5/articles/251/

6. Зимаков В.П., Лаврентьев С.Ю., Соловьев Н.Г., Шемякин А.Н., Якимов М.Ю. Пространственная и временная нестабильность оптических разрядов // Физико-химическая кинетика в газовой динамике. 2018. Т.19, вып.4. http://chemphys.edu.ru/issues/2018-19-4/articles/754/

7. Lavrentyev S.Yu., Solovyov N.G., Shemyakin A.N., Yakimov M.Yu. Gasdynamic effects in optical discharges produced by periodic pulse femtosecond laser // J. Phys.: Conf. Ser. 2019. V. 1250. P. 012027.

8. Philipp A., Lauterborn W. Cavitation erosion by single laser-produced bubbles // Journal of Fluid Mechanics, 1998, 361, pp. 75-116.

9. Han B., Köhler K., Jungnickel K., Mettin R., Lauterborn W., Vogel A. Dynamics of laser-induced bubble pairs // J. Fluid Mech. 2015. V. 771. Pp. 706-742.

10. Bhuyan M.K., Soleilhac A., Somayaji M., Itina T.E., Antoine R., Stoian R. High fidelity visualization of multiscale dynamics of laser induced bubbles in liquids containing gold nanoparticles // Scientific Reports. 2018. 8:9665.

11. Couairon A., Mysyrowicz A. Femtosecond filamentation in transparent media // Physics Reports. 2007. V.441. Pp. 47-189.

12. Boyd R.W. Nonlinear Optics, Third Edition. Academic Press, Inc. Orlando, FL, USA, 2008. 613 p. 
13. Fibich G., Gaeta A.L. Critical power for self-focusing in bulk media and in hollow waveguides, 2000, Optics Letters 25(5), pp. 335-337.

14. Kedenburg, S., Steinmann, A., Hegenbarth, R., Steinle, T., Giessen, H. Nonlinear refractive indices of nonlinear liquids: wavelength dependence and influence of retarded response // Applied Physics B, 2014, 117, pp. 803-816.

15. Zhao P., Reichert M., Benis S., Hagan D.J., Van Stryland E.W. Temporal and polarization dependence of the nonlinear optical response of solvents // Optica, 2018, 5(5), pp. 583-594.

16. Kedenburg S., Vieweg M., Gissibl T., Giessen H. Linear refractive index and absorption measurements of nonlinear optical liquids in the visible and near-infrared spectral region // J.Optical Materials Express, 2012, 2(11), pp. 1588-1611.

17. Devi P., Lozovoy V.V., Dantus M. Measurement of group velocity dispersion of solvents using 2-cycle femtosecond pulses: Experiment and theory // AIP Advances, 2011, 1, 032166.

18. Shneider M.N., Semak V.V. Laser induced ponderomotive convection in water // Journal of Applied Physics 2016, 120, 244902

19. Wang Y., Zhang Q., Zhu Z., Lin F., Deng J., Ku G., Dong S., Song S., Alam M.K., Liu D.,Wang Z., Bao J. Laser streaming: Turning a laser beam into a flow of liquid // Sci. Adv. 2017.3 : e1700555 